\title{
Ecosystem methodology for the development of the scientific potential of the network interaction of economic agents in the digital environment
}

\author{
Nataliia Simchenko ${ }^{1}$, Svetlana Tsohla $^{1}$, and Viktor Fursov ${ }^{2}$ \\ ${ }^{1}$ V.I. Vernadsky Crimean Federal University, 295097 Simferopol, Russia \\ ${ }^{2}$ North-Caucasus Federal University, 355017 Stavropol, Russia
}

\begin{abstract}
The paper considers the study of the problem of the development of the scientific potential of the network interaction of economic agents in the digital environment based on the ecosystem methodology. The study of this problem was based on the use of analytical methods for reviewing the scientific interdisciplinary literature of international databases, methods for analyzing the digital transformation of management relations "ecosystem is a management system of an organization", as well as methods for integrating heterogeneous economic data on the development of economic relations in the development of platform ecosystems. The most important result of the research is the conceptual substantiation of the formation of the scientific potential of the network interaction of economic agents based on the ecosystem development of forms of technological entrepreneurship and lifelong learning. The ecosystem methodology proposed by the authors is based on the identification of three types of relations "ecosystem is a management system": intersystematic relations; relations of intra-organizational regulation; platform management relationship. The significance of the results obtained is due to the importance of developing the economy of ecosystems on the basis of interdisciplinary network integrativity of the interaction of economic agents in the digital environment.
\end{abstract}

\section{Introduction}

The modern development of digital technologies radically changes the concept of sustainable development of society, makes serious changes in the structure of economic systems, which leads to the need to rethink the possibilities of science and technology based on the ecosystem development of the scientific potential of interaction between economic agents. The growing contradictions between the increase in the level of development of digital technologies and the loss of the sustainability of the development of economic systems requires the platform introduction of new business models, stimulating the development of new forms of technological entrepreneurship in industry based on breakthrough information technologies, which will create new jobs. The relevance of solving the scientific problem of developing the scientific potential of the interaction of 
economic agents in the digital environment is due to the need to address the escalating social and economic threats of the loss of stability of systems, the growth of intellectualization and dematerialization of technologies in the digital environment, the applied nature and needs of modern society in ensuring sustainable economic development on the principles of the new consistency and transformation of models for the development of the scientific potential of the interaction of economic agents in the digital environment.

\section{Materials and Methods}

The study of the prerequisites for the formation of an ecosystem methodology for the development of the scientific potential of the network interaction of economic agents in the digital environment was based on the use of analytical methods for reviewing the scientific interdisciplinary literature of the Scopus, Web of Science databases for the development of ecosystems and their impact on the economic development of organizations. Methods of institutional analysis of digital transformation of management relations "ecosystem is a management system of an organization", as well as methods of integration of heterogeneous economic data on the development of economic relations in the development of platform ecosystems are used. The application of the AI-methodology to the formation of models of technological entrepreneurship as an institutional-environmental toolkit for the development of the economy of ecosystems has been substantiated.

\section{Results and Discussion}

The scientific significance of this problem is due to the development of the fundamental principles of the new systemicity and conceptual provisions of the economy of ecosystems in the digital environment based on the integration of scientific achievements in the field of general systems theory, management theory, institutional theory, evolutionary economic theory, the paradigm of sustainable development, the paradigm of the digital economy, theory entrepreneurship, the theory of platform economics and the formation on this basis of a new pioneering theory of ecosystems, which provides, among other things, a new systemicity as the ability of the system to long-term sustainable independent functioning due to the network circulation of resources.

In economic science, the concept of an ecosystem arose as an intermediate between the concepts of "the economic agent" and "the market" [1]. In general, agent models are widely used in complex environments. According to the Oxford American Dictionary an agent is a person or someone who plays an active role or produces a certain effect. Also, an agent is understood as a firm, organization or socio-technical environment that ensures the receipt and increment of the effect [2].

The socio-economic ecosystem is a localized complex of organizations, business processes, innovative projects and infrastructural formations, capable of long-term independent functioning due to the circulation of resources, products and systems [3].

In this paper, we consider the ecosystem as a platform model for the interaction of economic agents in ensuring integrative sustainability based on breakthrough digital technologies.

The problematic of studying the principles of new consistency in the development of economic systems is due to the prevailing importance of the platformization of economic relations. New systemicity is characterized by permanent systemic changes in the structure of the system, which allows us to assert, based on the essential characteristics of the methodologies of hierarchical and network topology of systems, about deep changes in the classical postulates of systems theory regarding the primary functions and secondary 
structure. Consequently, the traditional approach to generating the economic value of goods in the economy based on the development of network effects is radically changing. It is important to take into account the principles of the new systemicity in the process of regulating the activities of ecosystems in ensuring their sustainable independent functioning over a long period.

The concept of ecosystems has received a lot of attention around the world by leading scientists, international organizations and national governments. On the one hand, in many foreign publications the ecosystem is considered from the standpoint of sustainable development of a circular economy, or circular economy. According to experts, due to population growth, the number of consumers is increasing and more and more resources are required for life support. Opportunities for economic growth should be separated from the consumption of raw materials and energy resources. New technologies and the transition to a circular economy provide the opportunity and benefits of environmentally responsible growth with limited resources $[4,5,6]$.

The studies carried out by BEROC scientists in the development of the circular economy made it possible to note the emergence of various risks in the implementation of R-imperatives, which are inevitable and due to the different level of development of the countries of the world. An obvious way to resolve possible conflict situations is the differentiation of responsibility of countries - the most developed are assigned a dominant role in the design and development of circular systems, and the developing ones need to revise the strategies and ways of solving their urgent challenges from the perspective of including circular models $[7,8]$.

On the other hand, in modern scientific publications, the problems of the formation and development of entrepreneurial ecosystems that create new consumer value and represent intermediate structures between the firm and the market are considered $[9,10,11,12,13$, $14,15]$.

In our opinion, the approach of A.A. Morozova, O.V. Staroverova regarding the consideration of the digital ecosystem not only from the point of view of information technology, but also as a targeted transformation of the economy [16]. In this regard, scientists distinguish three layers of the digital ecosystem: technological; managerial; consumer [16].

Let us consider the features of the application of the ecosystem methodology to the development of the scientific potential of the interaction of organizations through the prism of the formation of models of technological entrepreneurship in the field of the introduction of digital twins as an institutional and environmental toolkit for the development of the economy of ecosystems. Figure 1 shows the structural and functional relationships in the interaction of economic agents in the digital environment.

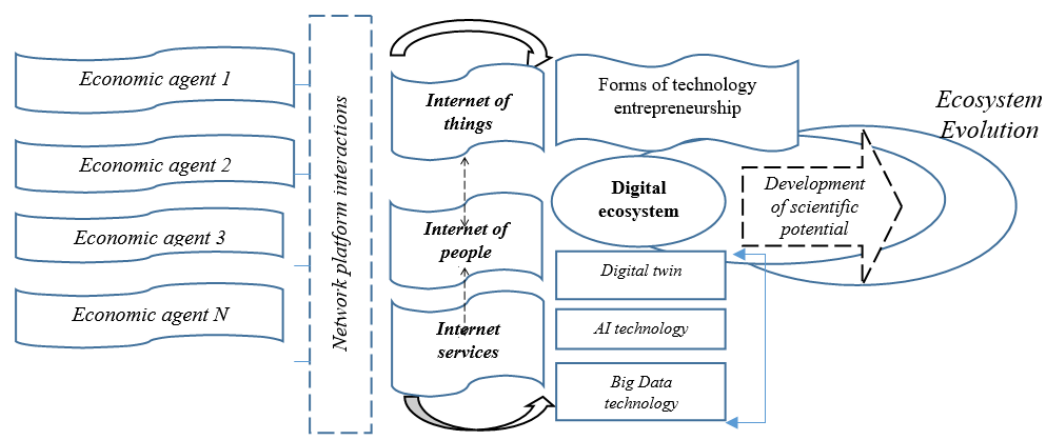

Fig. 1. Structural and functional ties in the interaction of economic agents in the digital environment Source: compiled by the authors. 
The interaction of economic agents in the digital environment is carried out on the basis of breakthrough technologies using the platforms of the Internet of Things, the Internet of People, and the Internet of services. It is advisable to ensure the development of the scientific potential of the interaction of economic agents on the basis of ecosystem methodology using forms of technological entrepreneurship. The characteristic features of technological entrepreneurship are the following: 1) supply creates demand; 2) innovations predetermine the development of society, technologies and services; 3 ) transformation of the criteria for the effectiveness of innovation in the direction of generating new services and products, and not exclusively in reducing the manufacturer's costs.

In the context of digital transformations in the management of organizations, data, not real assets, become a strategic asset for a company. The development of digital twin platforms in a company predetermines the formation of an ecosystem as a natural system environment of a company, which allows economists to study both the market as a whole and the intermediate structure between the market and the company $[2,26]$. The digital twin, as a virtualized model of a physical object, plays a critical role in the digital transformation of an organization. Based on the need to process a significant amount of big data, digital twin technology has given a kind of impetus to the development of artificial intelligence (AI) technologies and big data technologies.

Digital transformations of management relations determine the feasibility of conducting further research in the field of applying the AI methodology to the formation of models of technological entrepreneurship in the field of introducing digital twins as an institutional and environmental toolkit for the development of the ecosystem economy.

The author's interpretation of the ecosystem methodology for the development of the scientific potential of the network interaction of economic agents in the digital environment is based on the principles of a new systemicity, reflecting the variability of the manifestation of the postulates of the general theory of systems regarding the primary functions and secondary structure. Of course, this provision does not imply the exclusive dominance of the "structure" category over the "functionality" category in the systemic methodology for managing organizations, but it shows the importance of the dominant trends in digital transformations in the management of facilities.

\section{Conclusion}

The problematic of studying the principles of new consistency in the development of economic systems is due to the prevailing importance of the platformization of economic relations. New systemicity is characterized by permanent systemic changes in the structure of the system, which allows us to assert, based on the essential characteristics of the methodologies of hierarchical and network topology of systems, about deep changes in the classical postulates of systems theory regarding the primary functions and secondary structure. Consequently, the traditional approach to generating the economic value of goods in the economy based on the development of network effects is radically changing. It is important to take into account the principles of the new systemicity in the process of regulating the activities of ecosystems in ensuring their sustainable independent functioning over a long period.

\section{Acknowledgements}

The reported study was funded by RFBR according to the research project №19-01000346 . 


\section{References}

1. J. F. Moore, Predators and Prey: A New Ecology of Competition. Harvard Business Review, 75-86 (1993)

2. C. Stary, Sensors, 21(4), 1-24 (2021)

3. G. B. Kleiner, Economic revival of Russia, 1(59), 40-45 (2019)

4. G. Bressanelli, F. Adrodegari, M. Perona, N. Saccani, Sustainability (Switzerland), 10(3), 639 (2018)

5. A. Best, L. Duin, M. Chelminske, Macroeconomic and societal impacts of mainstreaming the circular economy (2018)

6. J. Brinkman, Waste to Wealth. Creating Advantage in a Circular Economy, 24, http://ec.europa.eu/

7. M. A. Gur'eva, V. V. Butko, Journal of International Economic Affairs, 9(4), 2367 (2019).

8. N. Tura, Jy. Hanski, T. Ahola, Journal of Cleaner Production, 90-98 (2019)

9. V. A. Karpinskaja, Materials of the Second conference of the Department of Modeling of Production Facilities and Complexes of the Central Economic and Mathematical Institute of the Russian Academy of Sciences, 2, 125-141 (2018)

10. G. B. Klejner, System analysis in economics - 2018: collection of works of the V International scientific and practical conference - biennale (November 21-23, 2018) / under total. ed. G. B. Kleiner, S. E. Shchepetova, 5-14 (2018)

11. Ju. N. Androsik, Economics and Management: Proceedings of BSTU, 7, 38-44 (2016)

12. S. V. Doroshenko, Journal of Economic Theory, 4, 212-221 (2017)

13. S. K. Mazhitova, B. K. Dzhazykbaeva, I. V. Denisov, M. A. Polozhishnikova, E. S. Petrenko, Economics, Entrepreneurship and Law, 10(3), 601-614 (2020)

14. A. Balli, İşletme Araştirmalari Dergisi Journal of Business Research-Turk, 12(2), 1058-1071 (2020)

15. L Griessbach, K. Ettl, Journal of East European management studies, 171-150 (2020)

16. L. Satalkina, G. Steiner, Sustainability, 12, 4018 (2020) 